\title{
Error Analysis of Kurdish EFL Undergraduate Learners' Accuracy in Speaking English Language
}

\author{
Bahra Taib Rashid \\ Department of English Language, University of Sulaimania, Kurdistan Region, Iraq
}

Email address:

Bahra.rashid@univsul.edu.iq

\section{To cite this article:}

Bahra Taib Rashid. Error Analysis of Kurdish EFL Undergraduate Learners' Accuracy in Speaking English Language. International Journal of Language and Linguistics. Vol. 3, No. 6, 2015, pp. 448-454. doi: 10.11648/j.ij11.20150306.29

\begin{abstract}
Using a multiple-case embedded research design (Yin, 1994), this study examined the nature of EFL learners who are learning or acquiring English language as a foreign language. The purpose of this project is to explore the errors/mistakes that might be made by the Kurdish EFL undergraduate learners, with the causes behind them and try to find out the appropriate method to apply it with the foreign language learners in order to learn English language. The data which were collected from them were analyzed in order to explain their errors or mistakes. It would be useful to find out the reasons behind them for those who care about how the English language is learned, and try to find out the appropriate theory to apply it with the FL learners in order to learn it. The data was collected in various ways in order to evaluate their mistakes. This assignment highlights the following aspects: the literature overview of the theories of FL learning, then the methodology, which deals with the two cases, next, participant analyses and finally the conclusion will be presented. The results served as contrasting and to some extent similar case studies. Results suggested that the best way for learning a new language can be through communication and involvement. Examples of evaluating each case were shown. Though, in the analysis there is an indication to the socio-cultural and cognitivist theories are more satisfactory and appropriate than behaviourism in the SLA field, possibly behaviourism is more significant to understand some parts of their history in order to know how they have been taught. On the other hand, this study cannot be generalized due to the small number of the participants and also different personality might have different ways to learn and acquire English language.
\end{abstract}

Keywords: Analysis, Behaviourism, Cognitivist, Socio-cultural, EFL, Errors, Mistakes, SLA, Speaking Fluently \& Communication

\section{Introduction}

The aim of this study is to highlight the best way (s) and theory(s) that people learn or acquire English language through. Linguists made an important distinction between language acquisition (LA) and language learning (LL). LA is "The process of learning a native or a second language (L2). The acquisition of native languages is studied primarily by developmental psychologists and psycholinguists", (Haynes, 2011: N/p). When Children acquire a language they learn it unconsciously and unaware of grammatical rules. This is similar to the first language acquisition. The quantity is more important than the quality. According to Ellis (1997), second language acquisition (SLA) can be defined as the way that people learn another language beyond their mother tongue in different environments. In line with this Haynes (2005) states that, young students need plenty of practices in the process of acquiring English through communicating with their classmates.

On a global level, English is a universal language that full of difficulty and complexity for the foreign and (L2) learners. According to Collins (2003: N/P) L2 Is a language other than the mother tongue that a person or community uses for public communication, especially in trade, higher education, and administration."

According to the British Council population around 375 million speak English as a L2 and soon they will increase to be more than who speak it as a first language (L1), (Burns and Coffin, 2001). The last three centuries, lots of powerful or developed countries imposed the developing countries to learn the English language as a L2, for business sake or travelling and communicate with people even beyond their local speech communities. So, people have to learn a L2 not just as an enjoyable hobby, but also as a means of obtaining 
an education like studying in abroad or securing employment, if one speaks English well, he can gain good jobs (Ellis, 1997).

Undoubtedly, English is the most widely, read, taught and spoken language that the world has ever known; this can be seen clearly when sometimes the English language of small island nation could have advanced and spread to this state, because of the globalization of English language (Kachru and Nelson, 2001). However, according to Graddol's (1997) cited in Harmer (2007) prediction; there are a number of possibilities of growing other languages like Hispanic in the USA to be the lingua-franca. According to the British Council at BBC NEWS, (n/d) there are more than 57 countries who are speaking English, some of them English is the official language or widely spoken. Over two billion are native English speakers. It is believed that approximately 750 million people speak English as a foreign language. Quarter of the world's population speak English to some level of competence. Recently demand to learn English language will be increased dramatically to be a temporary phenomenon with the first-wave effects in period of global change, (Burns and Coffin, 2001). The growth of a global economy has contributed in spread of English language. For instance, evolution of technology, in telecommunication networks, the television markets, immigration, colonilization, and educational development which lag behind the needs of workers and employers, (Burns and Coffin, 2001). According to Crystal (2003: 567).

"globalisation is changing the environment in which English is learned as a foreign language (EFL) or (ESL). First, economic and cultural globalisation includes the globalisation of language, and in particular the spreading role of English as a universal global lingua franca"

This means the globalization is changing with the way people communicate, people may have a problem with phoneme. For instance, people around the world pronounce English in different ways. English is a dynamic language because they have to revise the dictionary; they take out words and add new words each year. Perhaps because of these changes, English becomes a difficult language to learn.

Moreover, the internet has a significant impact on the global use of English. Ten years ago $90 \%$ of the internet hosts, websites and majority of traffic were based in Englishlanguage speaking countries presently; the users in different countries and other languages have to communicate with others in the cyberspace community in English (Burns and Coffin, 2001). As there are many universities and schools using technological tools for teaching and all of them are in English.

\section{Literature Review}

Learning a language is one of the interacted process that have been explained by several learning theories. In order to illustrate how FL is learned, it is worthwhile to know how L2 and L1 are acquired. To answer this question it is significant to consider three keys theories related to language learning, as these could be useful when analyzing the case studies.

Behaviorism theory is a bit dated and quite rightfully these theories have come to be challenged (John and Sharan, 1995). However, it is still significant to understand the basics behind behaviourist theories because it might be thought that some L2 learning is still very behaviourist based or some aspects of it still relevant, but not whole program of lesson based on behavoiurism. Skinner believes that learning is taken place through repeating actions, stimulus-response reaction of human to different situations (Rubin, 2011). Behaviourists argue that, through imitation and habit formation that language will be learned, they believe that L1 interferes with the L2, (Lado, 1964, cited in Lightbown, and Spada, 1999). Additionally, behaviourists believe that in the learning process, when learners had the opportunity to practise the language and imitate the models, they would be rewarded if they made the correct response to given stimulus, while if they were incorrect they would receive negative reinforcement (Ellis, 1997). Moreover, behaviorism was often linked to the Contrastive Analysis Hypothesis (CAH), when there are differences between L1 and L2, errors occur as a result of interference when the learners transfer native language habits into the L2 (Maicusi et al, 2000). Moreover, L2 is acquired more easily when there are similarities between the structure of the L1 and L2, whereas, if their structures are different then the learner might face much difficulty in learning the target language, (Patsy and Spada, 2006). Another aspect of this theory is that they viewed error as:

'A symptom of ineffective teaching or as evidence of failure and they believed that when they occur they are to be remedied by provision of correct forms; that is to say, use of intensive drilling and over -teaching" (Maicusí et al, 2000: 169).

They assume that errors made by L2 learners might be products of the interference of the L1, such as the similarity in the structure between two languages, (Ellis, 1997).

As behaviourism became more questioned by linguistics, cognitive theory appeared as an alternative of behaviorism and criticized it. According to Cherry (2011) cognitive theory focuses on the improvement of a person's thought processes; it illustrates how these thoughts impact on our understanding. He adds, if you understand the language you are able to remember it. Then, innatism, which is the theory developed by Chomsky assumes that, everyone has innate ability to acquire language which called language acquisition device (LAD) (Ellis, 1997). According to Chomsky who believes that humans have innate rules to acquire and pick up the language of their environment, which is based on the hypothesis that innate knowledge of the principle of universal grammar (UG), (Mitchell and Myles, 2004). So, there are some rules that are stored in children's mind that enable them to expand their knowledge and understanding in relation to the grammar and principle of the native language, when they are in practice of the target language their (LAD) will begin to comprehend the parameter of the language (Mitchell and Myles, 2004). Then when learners try to apply what they have learned there will be a mixture between the L1 and L2 
structure which neither exist in L1 nor L2, this is called interlanguage (Ellis, 1997) Moreover, according to Ellis (1997) an interlanguage referred to a mental grammar that is viewed as system of abstract linguistic rules; they were constructed by the learner which underlies comprehension and production of the L2. For instance, in different kinds of errors, learners ignore some grammatical features to simplify the learning task.

Another aspect of cognitive theory is that it focuses more on acquiring rather than learning language Krashen and Seliger, 1975 (cited in Krashen, 2002: 2) states that,

Acquirers need not have a conscious awareness of the rules they possess, and may self correct only on the basis of a feel for grammaticality. On the other hand, conscious $l L$ is thought to be helped a great deal by error correction and the presentation of explicit rules."

However, Selinker (1972) cited in Troike (2006: 41) stresses that, LL development in SLA is different from the L1 acquisition by children, various cognitive process are involved in that, such as there is transfer of L1 in L2 learning. Furthermore, how the L2 is taught, the ways that learners try to communicate with others in the L2. However, over-generalization phenomenon exists in L1 and L2 learning, in which specific rules are applied too mostly of the similar examples (sometimes overgeneralization includes some of developmental errors), not all L2 learners can reach the same stage of language proficiency as native speakers. In some respect before they reach to the target language norm, they will cease their L2 development which might be related to the age of the learning, the younger L2 learner are less likely to fossilize than the older ones (Saville and Troike, 2006). Additionally, Tarone (1994) notes that a learner can reach to a certain point of the target language and then fossilize which is the central characteristic of any interlanguage, i.e. it stops to develop at some point in the target language. Fossilization means repeating the same mistakes for a long time (Tarone, 1994). It is unclear why some structures seem more likely to fossilize than others. However, it could be argued that the reason might be as a result of premature controlled process before it is native-like. Then according to Ellis (1997) indicates transfer of L1 to L2, which refers to the influence of the L1 to the learner's L2 acquisition. Learners use their L1 knowledge to construct their temporary rules, in learning a target language, but only if they believe it will help them in the learning task, or when they get sufficient knowledge about the L2 for transfer to be possible, (Selinker, 1971, Seligar, 1988 and Ellis, 1997 cited in Krashen, 2002). There are two types of transfer, positive: when a L1 structure or rule is similar to that in the L2 utterance; and negative: when a L1 structure or rule is different to that in the L2 utterance and considered 'error' also called interference, (Saville and Troike, 2006).

Another relative version of cognitive theory in the field of SLA that concentrates on $1 \mathrm{~L}$, is the five hypotheses of Krashen's monitor model. Firstly, acquisition-learning hypothesis, according to Krashen, 'acquisition' and 'learning' are two ways for adult L2 learner to develop knowledge of a
L2 which means children acquire the L2 in the same way that they pick up their L1 unconsciously, but they learn the rules and forms consciously. He confirms that learning cannot turn into acquisition because many speakers can speak fluently. However they have not learned rules, while those who know rules but they are unable to apply them, when they are paying attention on what they want to say more than how they are saying it (Lightbown and Spada, 2006). Secondly, the monitor hypothesis shows the ability of the learner to use the language consciously and realize his/her mistakes and he/she has the ability to correct them. It is the task of monitor to control the performance that fits into the structure. Thirdly, natural order hypothesis suggests that the target language is acquired by L 2 learners in predictable sequences. Then he states that the L2 and L1 are learned in the same order. The fourth one is Input hypothesis that completes the previous hypothesis in which the learner is given an input beyond his current level of language development. Krashen calls the learner's current stage of knowledge as 'i' and the next one as ' 1 ' and both comprehension and acquisition will occur if the input contains forms and structures just beyond the current level of competence in the language $(' i+1$ ') because if the learner does not receive a language above his current level, he will not pass to higher level (Gass and Selinker, 2008). Finally, affective filter hypothesis is responsible of permitting and preventing the comprehensible data from storing the input in the LAD due to some factors, such as, motives, needs and so on (Lightbown and Spada, 2006). Acquiring language involves social interaction between the learner and the language that he acquires. It related to learner's personality, Krashen predicts that a good language learner is an 'acquire', who firstly can acquire enough amount of the L2, and secondly, has a low affective filter to enable him to get benefit from this input for LA (Krashen, 2002).

Second language Learning has been updated by the emergence of a new theory which is socio-cultural theory, it takes into account the interaction among people. Interactionists argue that through conversational interaction much SLA takes place, (Lightbown and Spada, 2006). Another scale of interaction in SLA is Vygotsky's sociocultural S-C theory of human mental processing who assumes that due to interactions between individuals which consequently maximize cognitive development as well as language development, because this theory considered speaking and thinking as interrelated, (Lightbown and Spada, 2006). Lantolf extends Vygotsky's theory to SLA claims that the L2 learner will move to higher level when they interact with speakers of the L2 who are more knowledgeable than they are (Lightbown and Spada, 2006). However the notion of the zone proximal development ZPD is the critical aspect of Vygotsky's theory, in the ZPD a L2 learner performs higher than his level of individual proficiency with the help or support from interaction with advanced interlocutor (Lantolf, 2000). While the idea of ZPD specifies that if a task is too easy and too much assistance is provided, the development occurs as the learner acts more independently, (Lantolf, 2000). However, experiential research has shown 
the impact of social context and individual learner's ability affect the successfulness in SLA. For example, learners capability are different in learning L2 successfully, there are many factors for that like intelligence and aptitude, other factors like attitudes, personality and motivation, (Cook, 2008). Much of this research has based on socio-educational model of SLA which suggests that some attitudinal characteristics influence the learner's level of motivation and learn another language in high motivation, such as attitudes toward the learning situation and integrativeness which reinforce success in learning the language, (Dornyei and Schmitt, 1999). It would be interesting for better understanding of the impact that foreign language studies bear on attitudes and motivations, to compare learners' attitudes and motivations toward languages, especially when there is a significant difference between the popularity and desirability (the desire of learning language) of the substitute languages, (Dornyei and Schmitt, 1999). There are two kinds of motivation instrumental, that refers to professional reasons for learning a language while integrative motivation refers to positive attitude toward the target language group and possible merging into group, that reflect whether the learner determines with the target culture and people in some sense or reject them, (Cool, 2008).

Harley and Hart cited in Candlin and Mercer (2001) state that "A range of contexts measures of aptitude have been shown to be one of the strongest available predictor of success". Because of the social influence many learners learn a language more or less well or badly in the community, on the street or in the workplaces. They do not learn it in the classroom, (Candlin and Mercer, 2001). Where learners make use of the language on daily basis in personal, social, professional or academic interaction, they can make a rapid progress toward mastery of a L2 in context, (Candlin and Mercer, 2001).

To sum up, it shows that behaviorism could not explain SLA in terms of some of the errors are not interference of L1. While cognitive and $\mathrm{S}-\mathrm{C}$ theories have tried to answer the questions that the behaviorism could not explain them.

\section{Methodology}

In this project, there are two participants that were investigated in Sulaimani. One of them is Arab from Iraq and undergraduate student at the University of Sulaimani. Her L1 is Arabic English is a foreign language to her. She is twenty four (24) years old and her name is Nawal. She arrived to sulaimani in the beginning of September, 2012. She started to learn English in the $1^{\text {st }}$ stage of the intermediate school in Baghdad, when she was 12 years old. She had been taught English by using traditional method for two hours per-week. Her teacher was Arab who always used Arabic language in her explanation. The focus was on grammar only and not on communication language. They just taught her how to construct sentences which were grammatically correct. Although, she always watches American movies and now she is studying English, her English is not very good and she could not express and comprehend very well. She is open minded, ambitious and a shy girl. Now Nawal has a private native English teacher.

The second one is a Kurdish student who is studying English at the University of Sulaimani and her name is Sony. Her L1 is Kurdish and again English is a foreign language to her. She is twenty three years old and unmarried. She has been to Sulaimani since September, 2013, but before that she spent her childhood in Germany. She had been studying English for 15 years, at the $6^{\text {th }}$ stage in the primary school, her teacher was German, but in the university her teacher was English native speaker. She had been taught English in a deductive way in order to save curriculum time. Teachers in the primary just gave them some grammar rules and they had always been corrected. She used to be the top student and she wanted to get higher marks in order to enter the college that she wanted to. She is a confident, ambitious, open minded and successful person. She was unable to express herself very well, in other words, she is not good English speaker, but she has an ability to write well. Both of the case study subjects are living at Sulaimani now. Both of them are my students. The reason behind my choice was, to be able to talk, meet and collect information from them whenever I need to make notice on it and in informal situations in order they act naturally and the data would be more accurate. These pieces of information were collected from them once, through interviewing. I met them, six times formally and many times informally, in order to identify whether they are repeat the same errors or they are just a slip of the tongue. Sometimes they were asked deliberately in past or present tense to discover whether they are able to distinguish between them or not. Sometimes, I just listened to them when they were talking, in order to observe them naturally, whether they do the same mistakes or not. Moreover, the questions were about their experience in learning English language, if they are confident when they use it or not, about their motivation in order to identify their characters and ambitions which might be helpful in analysing the data that was collected from them through written/record interview, in order to notice their pronunciation and fluency in speaking. Moreover, to discover their orally language strengths and weaknesses. Then a series of open-ended questions were used in order to see if they have any grammatical mistakes or weaknesses in learning the language. Next, simple tests are used as well, to make sure that their mistakes are not just a slip of the tongue. These techniques were useful and helpful in analysing and explaining the problems that occurred during the investigation about the two participants as well their ability in using the English language. These explanations of the problems might be useful to find out the reasons behind them which could be avoided in the future learning process with the FL learners.

\section{Results and Discussions}

From the investigation conducted with the two participants one can notice that Nawal, the Arab, had had a limited formal 
instruction in English because of poor quality of didactic transmission at Baghdad schools. When she had arrived in Sulaimani she had regular opportunities to use English due to her communication with her teachers, especially private native speaker teacher. She is a representative of naturalistic theory which maintains that a learner learns and communicates in the language at the same time (the third hypothesis of Krashen). She started to study English again with the English native speaker and she is in progress. She had the ability to speak English confidently although she made many mistakes grammatically. Perhaps she had hypermotivation in acquiring language according to Krashen's fifth hypothesis, or according to (Dornyei and Schmitt, 1999) it might relate to the instrumental motivation, which refers to professional reasons for learning a language, because she wants to pass an examination and to get a good job with high salary, beside that she likes English very much. Her father encouraged her since her childhood and rewarded her when she had performed well. Another possibility might be because she learned the language in an informal way like socio-cultural theory emphasizes, for communicative purpose. She sometimes corrected herself when she said; $I$ worked in tourism company, which is a common mistakes among Arabs, because in Arabic language there is no indefinite articles such as 'a' and 'an'. This had been corrected by saying; I worked in a tourism company. This could be related to the Krashen's monitor hypothesis which means that she was aware of her mistakes and correct them in order to improve her speech and the mistake is related to fail in performance not in competence. She was much better than other Arabs in her performance, such as pronunciation, focusing on communication and she was not afraid of making mistakes. Probably because she had known that she had to learn from her mistakes, this means she had self-confidence and awareness of language acquisition.

On the other hand, she did not know how to use the past tense in her speech when she was talking about past with both regular and irregular verbs. For instance, I am boringed in Baghdad; this might be a performance mistake and overgeneralization, because of the weakness in the methodological procedures and its limited scope in her school. There are present and past verbs in Arabic. What they have to do is to change the present verb into past one but instead of adding suffix such as 'ed' they just change its movement. For example: in the present tense they put Vibrio at the end of the verb, while slot (opening) to transfer sign on the verb these tenses. Because of the gaps between the two languages and she had just taught in Arabic, she faced difficulties in speaking, comprehending, and grammatical situations. Since that in Arabic there is no /p/ sound and the alternative of it, is $/ \mathrm{b} /$ because both sounds are bilabial and have the same place of articulation, that's why she utters every $/ \mathrm{p} /$ in $/ \mathrm{b} /$. This makes negative transfer from one language to another which it is believed that the greater the differences between the two languages, the more negative transfer can be expected it as it is claimed by (Luo, and Gao, 2011). Hence, her use of Arab-glish is a clear indicator of L1 interference or interlanguage hypothesis. This might relate to the way that she had been taught in a very teacher-centered way with a limited speaking and free practice. Her teacher was following a grammar translation method, which is common in Baghdad. means one of the difficulties in the course of second language learning for its existence in different linguistic levels

As far as her vocabulary, she has limited and poor vocabularies since she was repeating the same one mostly. For example, I don't like cooking; I don't like washing too much. When she had been asked about her fathers' job she could not express it. This might related to her limited communication with others in English which affected her comprehension when she could not comprehend some of my speech. This limited external input might impede the aptitude that linked to the notions of exposure and listening to the surrounding language which according to (Candlin and Mercer, 2001) has a significant impact on learning a FL because language does not learn in the classroom. So it might relate to her personality and intelligence which was explained in the socio-cultural theory.

Although she was taught in grammar translation method, her grammar was still weak, especially with the use of the third person singular 's', when she talked about her sister: she like animals. She always go to the cinema with her friends. This error can be related to her competence, because she was unaware or forgot the grammar rules as she repeated that several times; or she might be fossilized, since she successfully sent her message and there is no pressure to improve her level and nobody corrected her, and also because she learned English for 12 years and still repeats the same mistake. This also could assume that she does not monitor herself. When I said the correct form in front of her several times, she did not notice that and remained on her mistake. Sometimes she monitored herself when she corrected herself, but others she did not. This leads to another interesting point in her personality that she had a favorable fossilization, because she did not want to change her accent (Arab-glish) she wanted to keep her own way of pronunciation which might relate to policy or cultural issue.

Moving on, to the second participant who was Sony a native speaker of Kurdish; she started to learn English when she was 10 years old. Although her teachers in the primary and secondary were not English until she attended the university, she has a motivation that propelling her progress in speaking as she said. She had learned English by acquiring grammar, listening to the BBC documentary, watching English movies and repeated after them until she learned the language. Her knowledge about English grammar and sentence order was very good. This assumed that since the primary she had been taught grammar and always she was corrected, where it is impossible for her to make mistakes, or it might be a sample of Krashen acquisition-learning hypothesis. They were following the deductive approach in teaching English in a teacher centered way. It might also relate to her personality such as aptitude and intelligence since she worked hard to be one of the top students. 
However, her vocabulary and ability to speak are limited. Although she was given words in order to memorize because they would be tested the following day and also she spent a year in New Zealand talking English. This was against her desire as she was an ambitious, clever girl who wanted to discover the rules herself, not to be told. This might become an obstacle in front of her progression. Other possibility is, her language might be fossilized, because she was studying English for 15 years, or because of insufficient input of the target language that she was exposed to, due to not using it often enough, as she relied on electronic dictionary.

Sony, was able to correct herself sometimes when she said, Grammar helps me to can make sentences. It had been corrected by: Grammar helps me to make sentences. This could be an indicator of monitor hypothesis when Krashen demonstrates that, the learner has the ability to correct himself which relates to the conscious language learning.

Although her knowledge about English grammar was quite good, she was still making some mistakes especially in the past tense. For example: When I graduate from high school, I find some language school in Germany. And we don't have class yesterday. These were mistakes in the structure that would be an indicator of the L1 interference, which reflects usage of elements from one language or the other when she depends on the structure of her L1 to produce a response. Additionally, since the two languages structure are distinctly different, so she made that mistake, or interlingual errors, or to unawareness of rules restriction which is deficient application of the rules. Moreover, it might be because of the false notion hypothesis, which explain the general features of rule learning and third development errors when the learner construct hypothesis about the target language based on inadequate experience. The use of Kurd-glish' is very obvious indicator of the phonetic influence of her L1, which is according to the cognitive theory it relates to L1 transference because it does not relate to the structure of the language, it just related to her performance which distort the meaning of the words and incomprehensible. Moreover, her pronunciation was not being corrected since she was able to send her message successfully and nobody pushed her to improve her pronunciation.

Furthermore, a common mistake among the FL learners is neglecting the indefinite articles. It was obvious in Sony's speech, for example: my mother is Kurdish teacher. It could be L1 interference, because in Kurdish there is no indefinite article, or it might be failed to perform, which means she has a knowledge about the language rule but unable to apply it according to Krashen's first hypothesis.

Another problem was in subject agreement. For instance: The teachers is Kurdish in the primary school. This might relate to fossilization, due to her long experience with the target language and since no one corrected her or motivated her to improve her shortages; or it might be due to lack of knowledge in this particular point of grammar which is called competence mistake, when the learner unaware of the rules, or she could be fossilized since the meaning is correct and she did not have any pressure to improve that.
To recap, it can be noticed that both cases had similarities in some points. For instance: both of them were confident; unable to speak English very well, both were learned English with the same methods of teaching, like grammar-traditional method and deductive approach. While outside school, the focus was on communicating as in socio-cultural theory when they interacted with others, and when they had watched movies and listened to the BBC then repeated after them. Both of them were taught English by teachers who were non native speaker of English. Both had poor vocabularies. None of them were able to use the past tense; both were keeping their accents in uttering English language that made it hard to understand it. Both of them seem to have instrumental motivation in acquiring language since they want to promote their position and get higher jobs. Because of the growth in their economy and the open door policy of the People's Republic of Iraq and Kurdistan, motivation studies within Iraq and Kurdistan are important. They are similar in terms of monitor hypothesis; they were aware of some aspects of the language and had the ability to correct themselves. Both like the English language.

\section{Conclusions}

English has become a lingua franca, because it is widely adopted for communication between two people who speak different languages and one or both of them are using English as a FL, (Harmer, 2007). This is the case for Nawal. English is a global language and Nawal was motivated to learn it because she wanted to obtain a good job with higher salary.

It also dealt with the theories that impact SLA and how language is acquired. SLA is a wide field and the cases were too small to draw a safe conclusion on. However it is possible to learn from individual experiences. It is hard to be rigid and to give an entirely result throughout the short observation of the two cases. In spite of that, they were very helpful in creating a critical thinking about the most applicable theories in SLA. From what have been discussed, it seems that communication is the best way of learning any language, and learners need to be exposed to the target language in its L1 or FL nature since their childhood, because young people have high capacity to learning and absorption. Unquestionably, each theory has strong and weak points which seem that one theory came to complete the shortcomings of the proceeded one. From the analysis and evidence it appears that socio-cultural and cognitivist theories have much more relevance than behaviourism to analysing the language and acquisition, and also more acceptable and applicable in the SLA field. While behaviourism perhaps more relevant to understanding some of their part history in how they have been taught. However, according to Lightbown and Spada (1999) it is elusive goal to reach to an agreement on the complete theory of LA.

The two participants seem that, they were satisfied with their way of sending messages regardless of the way they speak and the errors they did, because language at the end is a part of people's identity. However, there are many factors 
behind making errors although it is natural and associated with the nature of human being. Maicusi et al., (2000) state that errors could be comprehensible or predictable.

\section{References}

[1] Burns, A. \& Coffin, C. (2001) Analyzing English in a global context (a reader). Antony Rowe ltd, eEastbourne.

[2] Candlin, C. \& Mercer, N. (2001) English language teaching in its social context: a reader. Routledge.

[3] Cook, V. (2008) Second language learning and language teaching. London: Hodder education.

[4] Dieu, B. (2005) Some facts and figures about the English Language. Available http://the english dept.tripod.com/esc.html [Accessed: $11 / 10 / 20 \overline{1} 4]$.

[5] Dörnyei, Z. \& Schmitt, R. eds (2001) Motivation and Second Language Acquisition (Technical Report). University of Hawaii.

[6] Ellis, R. (1997) Second language acquisition. Oxford: Oxford University press.

[7] Gass, S. \& Selinker, L. (2008) Second language acquisition: an introductory course $3^{\text {rd }}$ ed. Mahwa, NJ: Lawrence. Erlbaum and Associates. Han, Z. \& Odlin, T. eds (2006)
Studies of fossilization in second language acquisition. Great Britain: MPG Books Ltd. Haynes, J. (2005). Language Acquisition vs. Language Learning.

[8] Harmer, J. (2007). The practice of English language teaching. Harlow: Longman Pearson Ed. Krashen, S. (2002). Second Language Acquisition and second language learning. Pergamon Press.

[9] Lantolf, J. ed (2000) Socio-cultural theory and second language learning. Oxford University press.

[10] Lightbown, P. \& Spada, N. (1999) How languages are learned. Oxford: Oxford University press.

[11] Lighbown, P. \& Spada, N. (2006). How languages are learned. $3^{\text {rd }}$ ed. Oxford: Oxford University Press.

[12] Luo, X \& Gao, J. (2011) Mechanisms Leading to Negative Transfer. Theory and Practice in Language Studies. Vol. 1, No. 5, pp. 507-510. 1: ACADEMY PUBLISHER Manufactured in Finland.

[13] Mitchell, R. \& Myles, F. (2004). Second Language Learning Theories. $2^{\text {nd }}$ ed. London: Arnold. Rubin, J. (2003-2011) From Pavlov to Skinner Box For the Advanced Science Hobbyist: Repeat Skinner's Box Experiment. Available at: http://www.juliantrubin.com/bigten/skinnerbox.html [Accessed: 30/10/2014].

[14] Troike, M. (2006) Introducing second language acquisition. Cambridge: Cambridge university press. 